\title{
Exercise stress echocardiography with cardiac function parameters in coronary artery bypass grafting function assessment
}

\author{
(D)Ana Fabris* \\ The Polyclinic for \\ cardiovascular diseases \\ and prevention Sveti Nikola, \\ Korčula, Croatia
}

KEYWORDS: exercise stress echocardiography, the coronary artery bypass grafting, deformation. CITATION: Cardiol Croat. 2021;16(1-2):49. | https://doi.org/10.15836/ccar2021.49

*ADDRESS FOR CORRESPONDENCE: Ana Fabris, Poliklinika za kardiovaskularne bolesti i prevenciju Sveti Nikola, Strećica 6, HR-20260 Korčula, Croatia. / Phone: +385-98-1704343 / E-mail: fabrisana@yahoo.com

ORCID: Ana Fabris, https://orcid.org/0000-0001-9588-6788

||||||||||||||||||||||||||||||||||||||||||||||||||||||||||||||||||||||||||||||||||||||||||||||||||||||||||

Introduction: A more quantitative method for evaluation of stress echocardiography is introduced by measuring deformation ${ }^{1-3}$.

Case report: A 69-year old woman, formerly fitted with a double CABG, presents to the Polyclinic as a result of a new chest pain and shortness of breath on exertion. Exercise stress echocardiography with cardiac function parameters is performed: during the exercise, no cardiac arrhythmias and ECG signs of myocardial ischemia are shown, but testing is interrupted due to the leg pain at $71 \%$ of the theoretical maximum frequency. Immediate postpeak color Doppler derived long-axis systolic strain rate significantly decreases in midanteroseptal and basal posterior segment and insignificantly decreases in midinferior segment. Immediate postpeak parameters of diastolic function are borderline. MSCT coronary angiography: LIMA-LAD is flowing smoothly, with adequate flow through the distal LAD and collateral opacification of PD and PL. Long-lasting plaques with abundant calcifications are evident in the proximal segment ACX, therefore it is impossible to determine the degree of stenosis. The venous graft (VSM-RCA) is occluded. Coronary angiography: LAD at the beginning of the middle segment is suboccluded (99\%), and then the competitive flow from the LIMA-LAD is seen. LIMA-LAD is in good condition and connection. After the attachment of the LIMA-LAD, LAD is diffusely altered with long, borderline (70\%) stenosis. Borderline (50\%) stenosis in the middle ACx segment is followed by a series of marginal changes. RCA is occluded at the end of the proximal segment. VSM-RCA bypass is of the proper flow and connection.

Conclusion: Exercise stress echocardiography with the cardiac function parameters may reveal the alterations in the CABG function.
RECEIVED:

December 4, 2020

ACCEPTED:

December 18, 2020

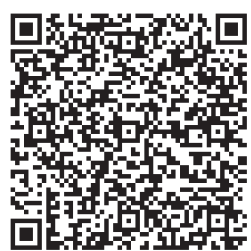

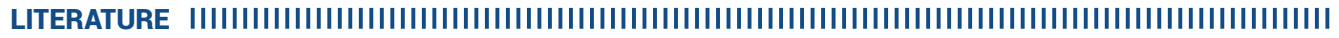

1. Sutherland GR, Di Salvo G, Claus P, D'hooge J, Bijnens B. Strain and strain rate imaging: a new clinical approach to quantifying regional myocardial function. J Am Soc Echocardiogr. 2004 Jul;17(7):788-802. https://doi.org/10.1016/j.echo.2004.03.027

2. Hanekom L, Cho GY, Leano R, Jeffriess L, Marwick TH. Comparison of two-dimensional speckle and tissue Doppler strain measurement during dobutamine stress echocardiography: an angiographic correlation. Eur Heart J. 2007 Jul;28(14):1765-72. https://doi.org/10.1093/eurheartj/ehm188

3. Caballero L, Kou S, Dulgheru R, Gonjilashvili N, Athanassopoulos GD, Barone D, et al. Echocardiographic reference ranges for normal cardiac Doppler data: results from the NORRE Study. Eur Heart J Cardiovasc Imaging. 2015 Sep;16(9):1031-41. https://doi.org/10.1093/ehjci/jev083 